\title{
Production of functional products using grape processing residuals
}

\author{
Sevda Macid MAMMADOVA ${ }^{1}$, Hasil Kamaleddin FATALIYEV ${ }^{1}$, Natavan Safar GADIMOVA ${ }^{1 *}$ (D), \\ Gulshan Razim ALIYEVA ${ }^{1}$, Azer Tapdig TAGIYEV ${ }^{1}$, Konul Vuqar BALOGLANOVA ${ }^{1}$
}

\begin{abstract}
The viticulture - winemaking of Azerbaijan has a rich history and traditions. Grapes have been cultivated and wine made in these places since the ancient times. In the 1980s, the field was in a boom period and provided economic benefits at a level comparable to the country's oil industry revenues. Although the area is currently experiencing a recession period, its development has been prioritized. During the processing of the grapes, a large amount of residues are formed, with the major proportion of the seedy pomaces. According to the weight of the grape bunch 3-7\% of comb, according to the weight of the seeds $15-20 \%$ peel, and 3-6\% seeds have been originated during the grape processing. Due to its rich content, these residuals are called secondary raw materials and their recycling can have significant economic benefits. Sometimes these residues are disposed of near processing facilities, polluting the environment and creating anti-sanitary situation. Therefore, the rational use of such residues have economic, environmental and other advantages. The peel, seeds and pulp of pomace from the grape varieties of Isabella and Bayanshira cultivated in the western region of Azerbaijan were studied. Spectra of the peel extract and chromatograms of peel hydrolysis were obtained from Isabella grape variety. Anthocyanidins of delphinidin, cyanide, peonidin and malvidin were found in the hydrolysis of peel extracts. Search-based studies have shown that the pomace of the Isabella variety is not only rich in biologically active substances but also has a high muscat aroma. With this in mind, the Isabella pomace was used for further research. Isabella grape variety is distinguished by the rich composition and organoleptic properties during the pomace processing. One of the best ways to bring it back to production is to use functional products with great perspectives in the modern world. To this end, the powder of Isabella pomace was extracted and have been applied in the production of functional products. The optimum variants have been determined in providing the best possible products with the addition to the yoghurt made from cow's milk with different amounts of pomace powder. The yoghurt which was made with the addition of $4 \%$ pomace powder was superior due to other trial samples for their content and quality. Although some changes were happened during storage, they were not negatively reflected in the composition and quality of the yoghurt samples and the product was selected with high organoleptic values even after 20 days of storage.
\end{abstract}

Keywords: grapes; juice; pomace; comb; peel; pomace powder; milk; yoghurt.

Practical Application: The powder obtained by grape pomace recycling process was used in the production of functional dairy products. Optimal parameters of pomace drying were determined, and the obtained pomace powder is rich with biologically active substances. The optimum amount of pomace powder was determined. Yoghurt, supplemented with pomace powder, has superior antioxidant properties, rich in biologically active substances and similar to musk scent. The results of the study can be used in processing plants producing juice and dairy products.

\section{Introduction}

Azerbaijan is one of the oldest land of viticulture and wine making. Looking at history, it is evident that the development of the field is not always on the ascending line. The field reached its highest level in the 1980s. In 1982, over 2 million tons of grapes produced from about 275,000 hectares of wine yards in the country. However, by the end of the last century and in the beginning of this century, the field has suffered severe losses and faced some sort of recession. At present, ongoing activities are being implemented for the elimination of current tension. At the same time, the processing of grapes and the effective use of the residuals are among the most important issues.

At the beginning of the 20th century, the American scientist Harold Hoteling published an article "The Economics of Lost
Resources" in the "Journal of Political Economy", which was devoted to the efficient use of resources, as well as their volume and value. It was pointed out that the residuals have had valuable products and a large amounts of money could be obtained by recycling. Any residual - could be raw material for the production of various products. Therefore, residuals should be treated as a secondary material reserves.

Over 60 million tons of grapes are produced every year in the world, with almost 23 million tons of share of European grape suppliers (Food and Agriculture Organization of the United Nations, 2014).

Approximately $15 \%$ of grapes produced annually are being processed. Solid residuals are presented in up to $30 \%$ of the raw 
material used during processing. Biodegradable solid materials including combs, bark and seeds refer to winery residuals. The useful properties of biologically active compounds, both in vitro and in vivo, have been discovered in residuals. Comprehensive extraction methods of phytochemicals and their use in human health have been evaluated in the residuals (Teixeira et al., 2014).

A group of researchers informed that most of the pomaces in grape processing was composted and buried in the soil for the completion of carbon cycle (Dwyer et al., 2014).

Other researchers pointed out that solids of grape processing can be harmful to the environment if not utilized at the required level. Thus, when the residuals are brought to the soil, they destroy the live being in the water by removing the streams and sources that contain rich nutrients (Vasconcelos Botelho et al., 2017). However, during the proper utilization, these residuals can be used as a useful raw material for other purposes. Although pomaces and seeds should be considered industrial wastes, it has a positive impact on human health in terms of its richness with vitamins, polyphenols, unsaturated fatty acids and nutritional components (Ribeiro et al., 2018). Therefore, the proper utilization of winery residuals is a progressive event from the economic, social, and environmental point of view.

The pomaces of grape is characterized by high amounts of phenol compounds, since they are not fully extracted in the winemaking process. These phenol compounds are secondary plant metabolites and can have useful effects on human health due to their active antioxidant, antimicrobial, anti-virus and anti-cold properties. Therefore, it is important to use efficient methods for sufficient extraction of phenol compounds from the pomaces of grape. Recent research has been made for the isolation of polyphenols from seeds in the study (Fontana et al., 2013).

Researchers suggest obtaining coffee and coffee substitutes from the pomaces of grape for this purpose, and recommend that the grape pomaces should be dried in a high-frequency electric field, mixing with other herbal ingredients, frozen, cryo grinded or granulated products. In addition, the production of new varieties of bread and bakery products from the processing of grape pomace flour have been suggested.

While squashing grapes, the separated comb is usually moistened with juice, and contains a certain amount of sugar. At a number of factories, the comb is squeezed, and each ton of grapes is extracted with 1 liter of combine juice. It is used in the manufacture of alcohol and vinegar. However, the use of these methods is of a casual nature. In most cases, the comb is used as fertilizer or animal feed (Gerasimov, 2003).

Investigations show that carried out research has yielded significant results in the study and utilization of residuals. However, it must be admitted that the carried out works were not at the provided level for the comprehensive solution of the problem. The residuals that are considered to be perspective ingredients in the processing of grapes have not been sufficiently studied yet. At the same time, we can not say that the potential resources for the production of combined products (joint expression of plant and animal products) are fully utilized. Apparently, there is an important scientific problem which has to be solved facing the field.
The purpose of the work is to effectively use the residuals generated during the processing of grapes by recycling processes and to prepare functional products.

\section{Materials and methods of research}

As the research object aboriginal Bayanshira which is cultivated in the country and the introduced Isabella grape varieties, the pomaces created during their processing; as well as cow's milk, yoghurt, devices and equipment are taken.

Isabella grape variety is characterized by a high resistance to phylloxera pests, odium, mildew, gray rot and also cold $\left(-32^{\circ} \mathrm{C}\right.$ frost tolerance). It is cultivated mainly in the mountainous and foothill areas of the western part of the country. Bayanshira is home to the Dashkesan mountainous region of western Azerbaijan. It is cultivated all over the country.

The grape pomaces produced during grape processing is dried in different temperatures $\left(50,70,90{ }^{\circ} \mathrm{C}\right)$ and time (50, 30 and 20 hours), as well as sublimation. The dry pomace specimens are then grinded on a coffee grinder and subjected to small porous $(0.3-0.5 \mathrm{~mm})$ slices. The pomace powder obtained is stored at a negative $20^{\circ} \mathrm{C}$ until analyzed in the associated polyethylene bags.

Cow milk for yoghurt is pasteurized at $90^{\circ} \mathrm{C}$ for 10 minutes. After cooling to $45^{\circ} \mathrm{C}$, starter culture (Chr. Hansen) is added to it. Pomace powder samples were dried at $70{ }^{\circ} \mathrm{C}$ in a drying wardrobe and in sublimator at $85^{\circ} \mathrm{C}$ and added to 2,4 and $6 \%$ amounts of milk and cultivated at $45^{\circ} \mathrm{C}$ in incubation room until it gets up to 4.4-4.6 $\mathrm{pH}$ level. Then, it is stored in a warehouse condition at $4 \pm 1{ }^{\circ} \mathrm{C}$ temperature.

In the working process, titrated acidity in the ready product, $\mathrm{pH}$ quantities, quantity of dry matter, color values, water reserves, the amount of total phenol compounds, antiradical activity, and other indicators are determined according to the available methods.

Color indicators ( $\mathrm{L}, \mathrm{a}, \mathrm{b})$ were determined using the Hunter-lab Colorflex-EZ device. $\mathrm{L}$ is an expression of clarity and darkness between $0-100,0$ is black, 100 is white, a $(+)$ positive value is a red, and a negative (-) is green. The positive $(+)$ value of the indicator $\mathrm{b}$ represents the yellow, and the negative (-) values indicate the blue.

The total phenol compounds are determined by spectrophotometer measurements of the color obtained by the Folin-Ciocalteu solvent.

The pomace is obtained by squeezing out the juice from the grapes and are peeled and separated in the microwaving conditions. The separated grape peel is frozen and dried in a minus $40{ }^{\circ} \mathrm{C}$ for $24-48$ hours. Before analysis, the peel samples are crushed until they become a fine powder.

For the extraction of grape peel samples, 2 and $1 \%$ hydrochloric acid in 50\% methyl alcohol is also extracted with 2 and $1 \%$ acetate acid solvents in 50\% methyl alcohol.

$0.25 \mathrm{~g}$; for the extraction of dried pomace samples with hydrochloride acid solvents; and for the extraction with acetate 
acid solvents is taken at $0.35 \mathrm{~g}$. After extraction, their volume is brought to $25 \mathrm{~mL}$ by extraction filters.

For hydrolysis of grape peel samples, 70\% methyl alcohol and $2 \%$ hydrochloric acid in $50 \%$ methyl alcohol is taken and for the last result $50 \%$ methyl alcohol regulated in the shape of $1,2 \mathrm{M} \mathrm{HCl}$ hydrolyzed at $85^{\circ} \mathrm{C}$.

In hydrolysis of $70 \%$ methanol grape pomace extracts, $15 \mathrm{~mL}$ of $70 \%$ methanol extract, $2 \mathrm{~mL}$ of methyl alcohol, $2.5 \mathrm{~mL}$ of $\mathrm{HCl}$ and $5.5 \mathrm{~mL}$ of distilled water are taken; in hydrolysis of grape peel extracts containing $2 \% \mathrm{HCl}$ in $50 \%$ methanol, $2 \%$ $\mathrm{HCl}$ extract in $15 \mathrm{~mL}$ of $50 \%$ methanol, $5 \mathrm{~mL}$ of methyl alcohol, $2.2 \mathrm{~mL}$ of $\mathrm{HCl}$ and $2.8 \mathrm{~mL}$ of distilled water mixture is used.

By the end of the process, the volume of hydrolysis is reached $25 \mathrm{~mL}$ with a mixture of $1.2 \mathrm{M} \mathrm{HCl}$ in $50 \%$ methyl alcohol. Then it is squeezed from microfilters and analyzed.

The HPLC method is carried out by chromatography SUPELCO C18 $(5 \mathrm{~nm}, 25 \mathrm{~cm} \times 4.6 \mathrm{~mm})$ column, using the elusion program.

Flow rate is $1 \mathrm{~mL} /$ minute. Determination is $280 \mathrm{~nm}$ and the wavelength is $520 \mathrm{~nm}$ for anthocyanidins. Before the injection of each sample, the column is rinsed for 10 min with $100 \%$ methyl alcohol and regulated for $10 \mathrm{~min}$.

\section{Results and discussion}

The Isabella variety has a distinctive musk fragrance, which is stored in its products for a long time. A comparative study of the Isabella variety with the local Bayanshira variety of the region, allow for better appreciation of its potential.

The residual pomace have been studied after the separation of juice on both varieties. The composition of the peel, seeds, and pulp have been included in the party of pomace had different grades on varieties.

Pectin was one of the highlighted substance in the studied pomace samples. It is known that $1.7-3.2 \%$ of the dry mass of the pomace is consisted of protopectin and in comparison with it, it is consisted of less than $0.11-0.63 \%$ of dissolved pectin.

Pectin substances were distributed unevenly in the peel, seed and pulp of the pomace.

Research shows that grape peels are the most valuable part of the grape berries, which is rich in biologically active substances. Although cellulose is the main structural unit of the cell membrane, hemicellulose and pectin are also found. The pectin content in the peel of Isabella grape variety was $0.57 \%$, but it was less than $0.20 \%$ in Bayanshira variety (Table 1 ).

A similar situation has been demonstrated in the amount of phenol compounds, flavonoids and other biologically active substances. Grape seeds make up 38-52\% of the dry pomace. This corresponds to $3-5 \%$ of the grape mass. Physio-chemical analysis of the composition of seeds in the experimental samples also yielded interesting results (Table 2).

Seed samples contain a large number of antioxidant polyphenols, including monomeric and oligomeric flavonoids. The number of flavonoids were significantly higher in the seeds of the Isabella variety (2.67\%) than Bayanshira (1.2\%).
Thus, Kanta Yadav and other researchers studied the effect of encapsulated (En) and none capsulated (NE) grape seed extract (GSE) at 1\% level added to milk before its fermentation was evaluated on the physicochemical properties, total phenolic content and antioxidant activity of the resulting yoghurt. Encapsulated GSE resulted in a product comparable to the control, based on sensory properties, acidity, water-holding capacity, viscosity and color, along with a threefold increase in total phenolic content and fourfold increase in antioxidant activity. The GSE addition resulted in no effect on the viability of Streptococcus thermophilus and Lactobacillus bulgaricus subsp. delbrueckii counts. The product with NE-GSE had poor sensory properties and laser polyphenol stability during storage as compared to En-GSE yoghurt (Yadav et al., 2018).

The number of natural polyphenols in the grape pomace depends on the variety of grape berries and the structural elements of the grape have been waved in a large intervals. The amount of phenol compounds was much smaller in the Bayanshira grape variety than in the Isabella variety. Looking at the main elements of the grape berries, it is clear that the bulk of the phenol compounds are in the peel and seed, and the smallest part is in the pulp. The bulk of the lignin seems to be in the seeds (16.5-25.1\%), and in small quantities (0.11-0.20\%).

As you can see, the highest amount of biologically active substances (polyphenols, vitamins, organic acids) are found in

Table 1. Indicators of physical and chemical composition of clay shell in the studied grape varieties.

\begin{tabular}{lcc}
\hline \multirow{2}{*}{ Content indicators } & \multicolumn{2}{c}{ Grape varieties } \\
\cline { 2 - 3 } & Bayanshira & Isabella \\
\hline Dry substances, \% & 14.0 & 17.1 \\
Proteins, $\mathrm{mg} / \mathrm{sm}^{3}$ & 5.4 & 6.2 \\
Total nitrogen, $\mathrm{mg} / \mathrm{dm}^{3}$ & 6.3 & 6.9 \\
Vibrating acids, \% & 6.5 & 6.7 \\
Hemicellulose, \% & 4.6 & 5.8 \\
Vitamin C, mg/100 g & 4.0 & 5.1 \\
Lignin, \% & 0.11 & 0.20 \\
Pectin, \% & 0.20 & 0.57 \\
Flavanoids, \% & 0.35 & 0.86 \\
Anthosians & 0.30 & 0.83 \\
Phenol compounds, $\mathrm{mg} / 100 \mathrm{sm}^{3}$ & 0.55 & 1.4 \\
\hline
\end{tabular}

Table 2. Physical and chemical composition indicators of seeds in the studied grape varieties.

\begin{tabular}{lcc}
\hline \multirow{2}{*}{\multicolumn{1}{c}{ Content indicators }} & \multicolumn{2}{c}{ Grape varieties } \\
\cline { 2 - 3 } & Bayanshira & Isabella \\
\hline Dry substances, \% & 51.2 & 59.4 \\
Total nitrogen, mg/dm dm $^{3}$ & 22.8 & 35.6 \\
Proteins, mg/sm ${ }^{3}$ & 19.6 & 29.4 \\
Cellulose, \% & 26.1 & 28.9 \\
Hemicellulose, \% & 9.2 & 11.2 \\
Vitamin C, mg/100 g & 1.96 & 2.39 \\
Tannins substances, \% & 1.8 & 3.6 \\
Pectin, \% & 0.30 & 0.48 \\
Lignin, \% & 16.5 & 25.1 \\
Flavonoids, \% & 1.2 & 2.67 \\
\hline
\end{tabular}


the Izabella grape variety, mainly in grape berries and seeds. As a result of the analysis, the Isabella variety pomace was selected as a biologically active material for future research.

One of the interesting things is that the amount of amino acids in the juice is significantly different compared to the amount of juice in the pomace. The juice contains 8 components of amino acid while the pomace contains 3 components of amino acid. Two of the ingredients found in the pomace (arginine and leucine) were higher than in the juice, and vice versa, the amount of proline was much smaller.

Research has revealed that the Izabella grape variety grown in the foothills of the Goygol region in the western part of Azerbaijan differs from those cultivated in the areas with more intense aroma and composition. After the processing of grapes from this region, some physical and chemical indicators of the pressed wet pomace were analyzed (Table 3 ).

It was found that the titrated acidity in the pomace from the Izabella variety grown in the foothills was $0.18 \%$ higher than in the lowland areas, the humidity was $1.73 \%$ less, and the $\mathrm{pH}$ indicator was less than 0.11 points.

The color values of the studied pomace samples (Hunter L, a, b) also differed. According to the results of the analysis, the $\mathrm{L}$ value of the wet pomace in Goygol region is 0.40 level higher than that of Samukh, a - less than 0.11 , and b - indicator was almost the same.

The analysis of the mechanical composition of the grape pomace shows that it contains mixtures including parts of the grape plant. In this connection, they need to be removed and homogeneous. It is preferable to rinse with regular water to prevent loss of biologically valuable substances at pomace. For this purpose the water is poured over the pomace and hand washed and the other mass is rinsed with water. Studies have shown that when the pomace is washed in water, its color shifts into water, at the same time water also contains large particles grape pomace that pass through the grapevine. Microscopy of sewage water has shown that they contain a large number of microorganisms. In this connection, the repeated washing of the pomace is carried out and the microbiological state of the final solution is closely monitored.

The moisture content of the dehydrated and fermented pomace grapes varied between 0.830 and $3.955 \%$. It has been shown that the drying temperature and method have a major influence on the humidity of the pomace.

Table 3. Some physicochemical features of the wet oilcake.

\begin{tabular}{lcc}
\hline \multirow{2}{*}{$\begin{array}{c}\text { Physical and chemical } \\
\text { indicators }\end{array}$} & Samukh & Unit \\
\cline { 2 - 3 } Vibrating acidity,\% & 1.36 & 1.54 \\
pH & 3.16 & 3.05 \\
Humidity,\% & 78.15 & 76.42 \\
Hunter color unit: & & \\
L & 9.36 & 9.76 \\
a & 17.22 & 17.11 \\
b & 1.72 & 1.71 \\
\hline
\end{tabular}

The amount of titrated acid in the pomace samples ranged from 4.36 to $5.18 \%$. As the temperature rises, there was an initial increase and then a decrease in the number of titrated acids. When it was dried in the sublimator, the amount of titrated acids was higher.

Hunter color values were determined in the pomace powders obtained using the various methods. It was found that the L prices varied from 21,994 to 25,446 for different variants, and the prices for a to $11,020-21,960$ and b to 3,146-6,790. Either L or A value of was higher than that obtained by sublimation drying, and $\mathrm{B}$ was obtained at a higher temperature drying $\left(90^{\circ} \mathrm{C}\right)$ in drying chambers and was 6,790.

Phenol compounds and antiradical activity of powder extracted from the Isabella grape variety pomace were investigated. It turned out that these indicators change depending on the drying method and temperature.

During drying at three different temperatures in ordinary drying chambers, the total phenol compounds varied between 18,760 and 25,630, while in the sublimation drying the total phenol compounds totaled $31,520 \mathrm{mg} / \mathrm{g}$. Antiradical activity was observed in experimental samples between $13,860-17,640 \mathrm{mg} / \mathrm{dm}^{3}$, and the highest value was observed in the lyophilic (sublimation) drying.

In conventional dryers, there was a slight increase in antiradical activity, and a decrease in $90^{\circ} \mathrm{C}$, with an increase in temperature during drying. As with the total phenol compounds, antiradical activity was also higher during sublimation drying.

The spectra of extracts from the peel of the Isabella grape variety are shown (Figure 1). It was found that the most suitable solvent for peel extracts of red grape variety is $2 \%$ hydrochloride acid in 50\% methyl alcohol.

Due to the extremely high glucosides in the peel and the difficulty in ensuring their standards, the peel extracts were hydrolyzed and the hydrolyzes were detected using standard additives of delphinidin, cyanide, peonide and malvidin. From this point of view, the extracts of the peel also contain glucosides of the mentioned anthocyanidins (Figure 2).

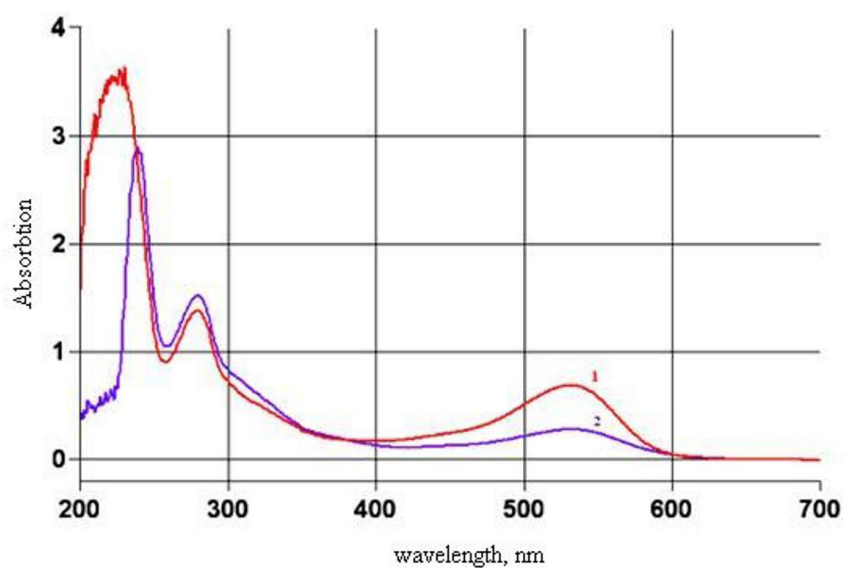

Figure 1. Spectrum of peel extract in the grape variety of Isabella $2 \%$ hydrochloride acid in 1-50\% methyl alcohol (red line); $2 \%-50 \%$ acetate acid in methyl alcohol (purple line). 
Due to the lack of the standards of peak shown by A in the extracted hydrolysates of the grape peel, anthocyanide of petunidin is assumed to be in the grape.

An analysis of the Izabella grape pomace variety indicates that it is rich in biologically active substances, particularly with antioxidants. The use of such residuals in the production of combined products is of great importance in terms of the acquisition of functional products.

The effects of adding dietary fiber-rich by-products to probiotic ice creams have been studied. For this purpose, fruit (grape, apricot, apple) and grain (rice, corn, sunflower, barley) based by-products were added to ice cream. The viability of Lactobacillus acidophilus (ATCC 4357D-5) and Bifidobacterium animals subsp. lactis (ATCC 27536) was determined with microbial analyses at 1, 15, 30 and 60 days of storage. In conclusion, it was shown that dietary fiber-rich by-products could be used in ice cream with improved survival of the probiotic strains without any adverse effects on the physicochemical, microbiological and sensory properties of the ice cream (Ayar et al., 2018).
We have carried out researches in order to make yoghurt that meets these requirements.

The milk used for making yoghurt contains $10.60 \%$ of dry matter, $3.25 \%$ of fat, titration acidity $0.14 \%$ and active acidity of 6.36 .

The yoghurt samples with the addition of pomace samples (without addition of control - pomace, with the addition of 2,4 and $6 \%$ pomace) dried by sublimation method (at $-85^{\circ} \mathrm{C}$ 24 hours) and in drying cabinets (at- $70{ }^{\circ} \mathrm{C}, 30$ hours) were analyzed (Table 4).

The addition of pomace powder affect the physical and chemical properties of yoghurt. As it can be seen, as the amount of added pomace powder increased, there was an increase in the amount of dry matter and titrated acidity in the yoghurt samples, and a decrease in $\mathrm{pH}$ amount. At the same time, there was an increase in antiradical activity and the number of phenol compounds. All these indicators were optimized at $4 \%$ of the added pomace powder. Yoghurt made by adding $4 \%$ pomace powder of Isabella grape variety, has been highly appreciated for its distinctive aroma and taste. The finished yoghurt product

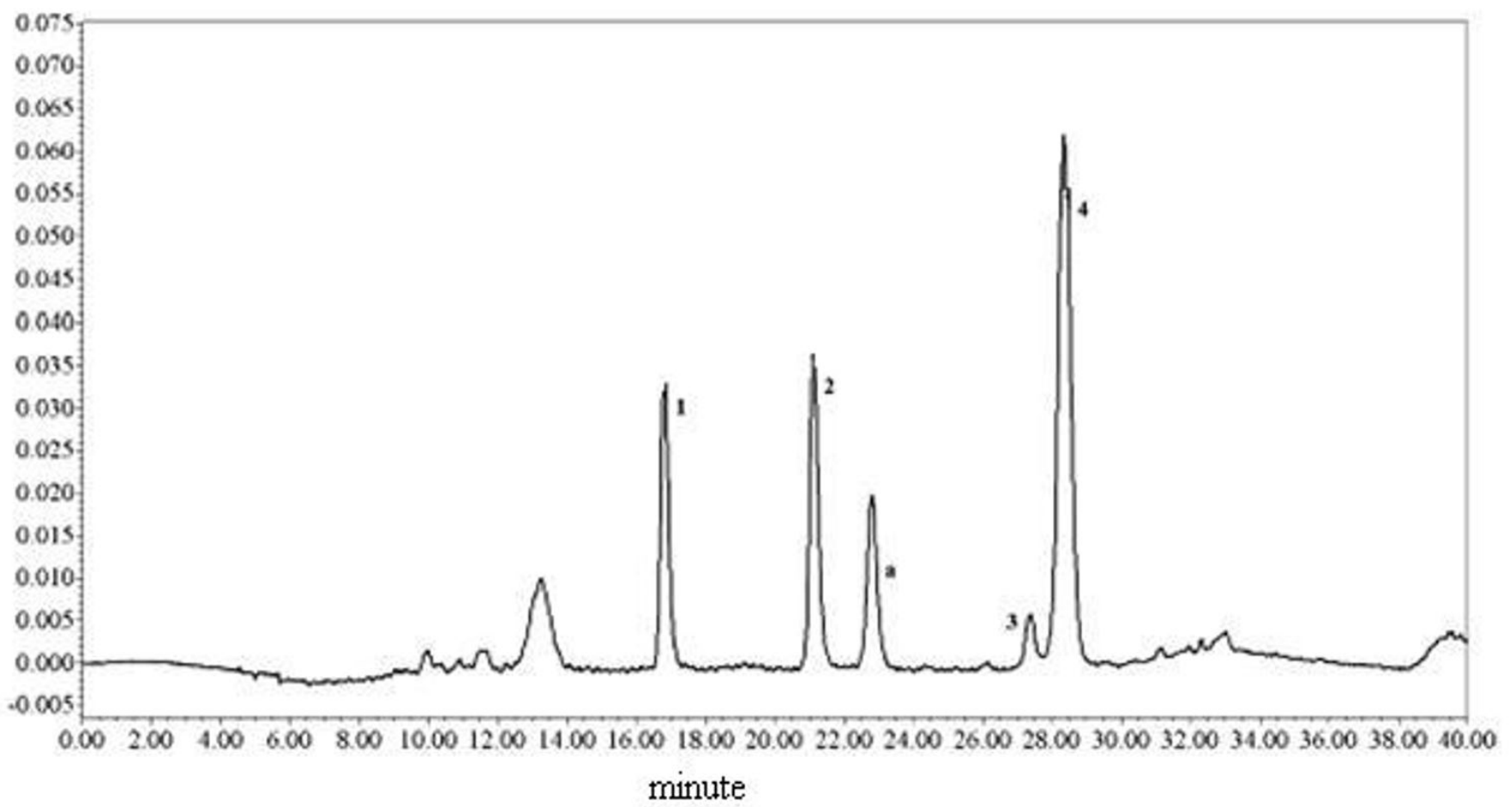

Figure 2. Chromatography of Isabella peel hydrolysis (520 nm wavelength). (1) delphinidin; (2) cyanide; (3) peonidin; (4) Malvidin; (a) Petunidin.

Table 4. Impact of the amount of the added oilcake on the physical and chemical parameters of yoghurt.

\begin{tabular}{|c|c|c|c|c|c|c|c|c|}
\hline \multirow{2}{*}{ Samples } & \multirow{2}{*}{$\mathrm{pH}$} & \multirow{2}{*}{$\begin{array}{l}\text { Vibrating } \\
\text { acidity,\% }\end{array}$} & \multirow{2}{*}{$\begin{array}{c}\text { Overall phenol } \\
\text { compounds, } \mathrm{mg} / \mathrm{kg}\end{array}$} & \multirow{2}{*}{ QM, \% } & \multirow{2}{*}{$\begin{array}{c}\text { Antiradical } \\
\text { activity, } \mathrm{mg} / \mathrm{dm}^{3}\end{array}$} & \multicolumn{3}{|c|}{ Hunter color unit } \\
\hline & & & & & & $\mathrm{L}$ & $\mathrm{a}$ & $\mathrm{b}$ \\
\hline $\begin{array}{l}\text { Outcome (without } \\
\text { adding night powder) }\end{array}$ & 4.05 & 0.72 & 106.20 & 10.36 & $2,306.5$ & 90.61 & -1.55 & 7.68 \\
\hline $2 \%$ addition & 4.14 & 0.70 & 192.31 & 11.41 & $1,230.05$ & 70.91 & 3.96 & 3.66 \\
\hline $4 \%$ addition & 3.95 & 0.75 & 305.60 & 13.01 & 520.60 & 57.22 & 6.75 & 2.40 \\
\hline $6 \%$ addition & 3.96 & 0.73 & 501.30 & 14.90 & 312.44 & 49.11 & 7.45 & 1.80 \\
\hline
\end{tabular}


Table 5. Changes during the storage of yoghurt with added oilcake powder (4\%).

\begin{tabular}{lrrr}
\hline \multicolumn{1}{c}{ Indicators } & \multicolumn{1}{c}{ Storage time, days } \\
\cline { 2 - 4 } & Initial & 3.84 & 20 \\
\hline $\mathrm{pH}$ & 3.90 & 0.83 & 3.80 \\
Vibrating acidity,\% & 0.77 & 2540 & 0.94 \\
Fiber, (cP) & 2985 & 445.01 & 3102 \\
Overall phenol compounds, $\mathrm{mg} / \mathrm{kg}$ & 510.40 & 390.64 & 498.21 \\
Removal of free radicals, $\mathrm{mg} / \mathrm{dm}^{3}$ & 342.05 & & 366.91 \\
Hunter color unit & & 56.90 & 57.32 \\
$\mathrm{~L}$ & 56.12 & 7.11 & 6.97 \\
$\mathrm{a}$ & 6.96 & 2.01 & 2.21 \\
$\mathrm{~b}$ & 2.16 & & \\
\hline
\end{tabular}

differs from its similar characteristics, especially with the specific fragrance of the Isabella variety.

In the work of Esmerino et al. (2017) Greek yogurt samples are characterized according to consumers perceptions using three different methodologies: Pivot Profile (PP), Check-all-that- apply (CATA), and Projective Mapping (PM). Also evaluated which method is easier for consumers to describe products. The rapid methodologies assessed were equally effective $n$ characterizing the different samples. They suggest the supplemental use of Multidimensional Alignment (MDA) as it shows more accurately the correlations between attributes and samples, especially in the case of PP data.

Changes in some physical and chemical parameters were observed during the storage of the functional purposed yoghurt (Table 5).

It can be seen that for 20 days of storage the $\mathrm{pH}$ decreased by 0.10 units and the titrated acidity increased by $0.21 \%$. Due to the additions, there was a decrease in the amount of fiber in the first ten days and an increase in the second ten days. In the total phenol compounds' amount, there was a decrease of about $12 \mathrm{mg} / \mathrm{kg}$ during a period of 20 days. One of the most important indicators was the elimination of free radicals, in other words, antiradical activity. If in the initial material this number was 342.05 , after 20 days of storage it was $366.91 \mathrm{mg} / \mathrm{dm}^{3}$.

All this was not reflected negatively in the composition and quality of the yoghurt samples, and after the storage, the product was characterized by high taste, aroma and other organoleptic properties.

\section{Conclusion}

The study carried out about the reproduction and functional purposed food products of grape pomaces created during the processing of grape. In the course of exploratory research, the introduced aromatic Isabella grape variety cultivated under the same conditions was compared to the Aboriginal Bayanshira grape variety. Grape varieties were processed separately and created sweet (non-fermented) pomaces were used.

It was found that the amount of pectin, flavonoids, phenol compounds in the peel of the Izabella grape variety was 2-3 times higher than that of Bayanshira grape variety. Vitamin C, lignin and hemicellulose amounts has also been found to be high.
An analysis of the seeds by species also showed a similar situation. Taking into account the results of the exploratory research, the pomaces from the Isabella variety was used for further research.

After the separation of its juice, the Isabella grape variety was washed, dried, grinded and powdered and then used for yoghurt production.

The cow's milk used for making yoghurt was pasteurized and cooled and then starter culture was added. The product was grown at $45^{\circ} \mathrm{C}$ until the ambient $\mathrm{pH}$ reached 4.4-4.6.

Yoghurt samples were prepared with the addition of pomace powder in different quantities of (2.4 and $6 \%$ ). The yoghurt made with $4 \%$ pomace powder addition is superior to other examples with its composition and quality. It has been found that pomace powder addition results in the reduction of free radicals and increasing the amount of food fibers and phenol compounds in yoghurt. The gained product was highly appreciated by the control samples, with their functionality, dietic features and aroma.

\section{References}

Ayar, A., Siçramaz, H., Öztürk, S., \& Öztürk Yilmaz, S. (2018). Probiotic properties of ice creams produced with dietary fibres from byproducts of the food industry. Journal of Dairy Technology, 71(1), 174-182. http://dx.doi.org/10.1111/1471-0307.12387.

Dwyer, K., Hosseinian, F., \& Rod, M. (2014). The market potential of grape waste alternatives. Journal of Food Research, 3(2), 91-106. http://dx.doi.org/10.5539/jfr.v3n2p91.

Esmerino, E. A., Tavares, E. R. Fo., Thomas Carr, B., Ferraz, J. P., Silva, H. L. A., Pinto, L. P. F., Freitas, M. Q., Cruz, A. G., \& Bolini, H. M. A. (2017). Consumer-based product characterization using Pivot Profile, Projective Mapping and Check- all-that-apply (CATA): a comparative case with Greek yogurt samples. Food Research International, 99(part 1), 375-384. http://dx.doi.org/10.1016/j. foodres.2017.06.001. PMid:28784495.

Fontana, A., Antoniolli, A., \& Bottini, R. (2013). Grape pomace as a sustainable source of bioactive Compounds; extraction, characterization, and biotechnological applications of phenolics. Journal of Agricultural and Chemistry, 61(38), 8987-9003. http:// dx.doi.org/10.1021/jf402586f.

Food and Agriculture Organization of the United Nations - FAO. (2014). FAOSTAT. Rome. Retrieved from http:/[faostat 3, fao.org/ faostat-gateway/go/to/download/Q/QC/E

Gerasimov, M. A. (2003). The use of waste wine. Journal of Wine Technology, 1, 183. 
Ribeiro, T. P., Lima, M. A. C., Alves, R. E., Gonçalves, A. L. S., \& Souza, A. P. C. (2018). Chemical characterization of winemaking byproducts from grape varieties cultivated in Vale do São Francisco, Brazil. Food Science and Technology, 38(4), 577-583. http://dx.doi. org/10.1590/fst.01116.

Teixeira, A., Baenas, N., Dominguez-Perles, R., Barros, A., Rosa, E., Moreno, D., \& Garcia-Viguera, C. (2014). Natural bioactive compounds from winery by-products as health promoters: a review. International Journal of Molecular Sciences, 15(9), 15638-15678. http://dx.doi.org/10.3390/ijms150915638.
Vasconcelos Botelho, R., Gabriela Datsch Bennemann, G., Reys Torres, Y., \& Jefferson Sato, A. (2017). Potential for use of the residues of the wine industry in human nutrition and as agricultural input. In A. M. Jordão \& F. Cosme (Eds.), Grapes and wines: advances in production, processing, analysis and valorization. Rijeka: IntechOpen.

Yadav, K., Bajaj, R. K., Mandal, S., Saha, P., \& Mann, B. (2018). Evaluation of total phenol content and antioxidant properties of encapsulated grape seed extract in yoghurt. International Journal of Dairy Technology, 71(1), 96-104. http://dx.doi.org/10.1111/1471-0307.12464. 